\title{
APRENDIZADO COLABORATIVO EM REDES SOCIAIS: UMA REFLEXÃO SOBRE AS POSSIBILIDADES DE CONTRIBUIÇÃO DO DESIGN
}

Daniel Maciel Costa da Silva

Dr. Carlos Eduardo Miranda

Resumo: As tecnologias de comunicação e informação, típicas do ciberespaço, tem contribuído para o rompimento com o espaço e o tempo específicos para a aprendizagem. Uma rede social pode ser definida como um conjunto de dois elementos: atores (pessoas, instituições ou grupos; os nós da rede) e suas conexões (interações ou laços sociais). Evidenciamos, neste cenário, as redes sociais, enquanto estruturas que dependem do engajamento dos indivíduos em processos interdependentes, determinam os diversos tipos de relacionamentos. A partir deste levantamento investigatório, identificamos a necessidade de evidenciar recursos projetuais aplicáveis nas interfaces, para conseguir que os usuários realizem o maior número possível de interações mútuas, além de levantar ações precedentes, tais como as estratégias, ferramentas e métodos específicos do design de informação, interação e de interfaces que possam motivar a colaboração entre seus usuários. Identificamos que, para tanto, será necessário compreender as teorias relativas ao aprendizado colaborativo para relacioná-las a estudos da cibercultura e do design de interações e interfaces. Concluímos que as metodologias e a lógica dedutiva do design podem contribuir na elaboração e prototipagem de serviços e interações digitais eficientes para estimular a colaboração e registrar e avaliar o aprendizado individual resultante de processos colaborativos.

Palavras-chave: design, educação, aprendizagem colaborativa, ensino inovador.

Abstract: Communication and information technologies, typical of cyberspace, has contributed to the break with the space and the specific time for learning. A social network can be defined as a set of two elements: actors (individuals, institutions or groups, as network nodes) and their connections (interactions or social ties). We show in this scenario, social networks, as structures that depend on the engagement of individuals in interdependent processes, determine the different types of relationships. From this investigative survey, we identified the need to show projective resources applicable interfaces, to get users to perform the greatest possible number of mutual interactions, as well as raising previous actions, 
such as strategies, tools and specific methods of information design, interaction and interfaces that can motivate collaboration among its users. We found that, for both, you must understand the theories relating to collaborative learning to relate them to the cyberculture studies and interactions and interface design. We conclude that the methodologies and deductive logic design can contribute to the development and prototyping services and efficient digital interactions to stimulate collaboration and record and evaluate the resulting individual learning collaborative processes.

Keywords: design, education, collaborative learning, innovative learning.

\section{INTRODUÇÃO}

A internet se tornou uma das principais ferramentas de trabalho e pesquisa para estudantes, professores e profissionais, estando cada vez mais presente nos domicílios, no trabalho, nas instituições educacionais e mais recentemente nos dispositivos móveis, como telefones celulares e tablets, que é comum carregar consigo durante quase todo o tempo. Um levantamento realizado pelo IBGE(2015) com dados de 2013 aponta que $88,4 \%$ da população brasileira tem acesso a internet através de computadores e $57,3 \%$ tem acesso através de dispositivos móveis como telefones celulares e tablets. O crescimento de $7,3 \%$ na utilização de dispositivos móveis em relação a 2013 aponta que há uma tendência para que um número cada vez maior de pessoas tenha individualmente uma conexão de internet disponível.

A maneira como os indivíduos se comunicam, aprendem e se inspiram para realizar novos projetos profissionais e pessoais vem sendo constantemente afetada pela distribuição de conteúdo em rede. A popularização de redes sociais digitais fez com que os laços interpessoais se tornassem mais facilmente rastreáveis e disponíveis. Essas características estabeleceram novos desafios, especialmente com relação à sistematização da enorme quantidade de conteúdo disponível instantaneamente e aos novos paradigmas comunicacionais.

A transição do modelo de redes centralizadas, na qual um emissor central propaga sua mensagem para inúmeros receptores, para as redes descentralizadas, na qual todos os nós da rede são potencialmente produtores e receptores ao mesmo tempo, aconteceu muito rapidamente e de forma violenta. Os papéis de produtor e consumidor dos conteúdos disponíveis online se confundiram de maneira profunda, estabelecendo novas potencialidades para a comunicação interpessoal e a colaboração, tornando mais evidentes e simplificados o acesso a conteúdos e demandas em nichos extremamente específicos.

As tecnologias de comunicação e informação, típicas do ciberespaço, tem contribuído para o rompimento com o espaço e o tempo específicos para a aprendizagem. Uma vez que os conteúdos e as relações sociais tendem a se tornar cada vez mais disponíveis e ubíquas, o aprendizado pode potencialmente ocorrer em qualquer lugar e a qualquer momento, não apenas na escola, na sala de aula e nos laboratórios. Neste contexto os professores não possuem mais o monopólio do aprendizado e compartilham a atenção e a confiança dos alunos com inúmeras outras 
fontes de conteúdo, muitas vezes mais atraentes e divertidas, completas, diversificadas ou adaptadas às suas necessidades particulares. Para Gui Bonsiepe (2011, 2015), as hipermídias parecem tão atrativas porque aparentemente facilitam a apresentação do saber não linear. Artefatos-multimídia são compostos de linguagem, imagem, som e música. Já os hipermídia combinam todos esses canais perceptivos e, além disso, permitem interação em modo de navegação entre nós semânticos. Elas parecem libertar-nos da rigidez das apresentações lineares. Contudo, não temos uma teoria coerente sobre a maneira como essas redes de conhecimento são estruturadas, pressupondo que tenham alguma estrutura. E muito menos sobre as diferentes formas de abordagem projetual a serem tomadas, em projetos de design orientados à otimização deste novo sistema de comunicação e aprendizado: as redes colaborativas.

\section{INTERAÇÕES E APRENDIZADO EM REDES SOCIAIS}

A respeito das interações em redes sociais, estudos anteriores foram muito eficientes em categorizar as relações e interações possíveis, estabelecendo como elas podem ser projetadas para funcionar em conjunto e contribuindo para reflexões sobre que tipos de reações é possível esperar de um determinado grupo ou recurso interativo estabelecido em uma determinada plataforma.

Uma rede social pode ser definida como um conjunto de dois elementos: atores (pessoas, instituições ou grupos; os nós da rede) e suas conexões (interações ou laços sociais). As redes sociais são estruturas que dependem do engajamento dos indivíduos em processos interdependentes de cooperação, competição ou conflito (RECUERO, 2010). Os relacionamentos entre os atores da rede podem ser descritos como laços e qualificados em quanto a sua força, dada em função da duração da relação, intensidade emocional, intimidade (confiança mútua) e serviços recíprocos (GRANOVETTER, 1973).

Por exemplo, a relação entre irmãos, de maneira geral, é de longa duração, alta intensidade emocional e alta intimidade, portanto o laço existente entre irmãos é extremamente forte. Já entre colegas de estudo a força dos laços pode variar bastante em função da proximidade de interesses, do estilo de comunicação estabelecido entre eles, do histórico de atividades realizadas em conjunto e até mesmo do sucesso dessas atividades. Os laços fracos são aqueles que apresentam maiores possibilidades de aprendizado tanto social quanto de informações novas uma vez que são constituídos entre pessoas potencialmente com mais diferenças de pensamento, informação e experiências. Já em relações de laços fortes nas quais os indivíduos já compartilham muitas experiências e pensamentos em comum e por isso talvez não tenham tanto a acrescentar à experiência um do outro.

Estes relacionamentos podem ser decompostos em um conjunto de interações. As interações são ações que têm um reflexo comunicativo entre o indivíduo e seus pares e podem ser qualificadas individualmente quanto à sua sincronia e ao tipo de relacionamento mantido. As interações síncronas são aquelas nas quais se espera que a resposta seja imediata. Geralmente ferramentas de interação síncrona permitem a participação dos indivíduos em eventos agendados previamente em horários e datas específicos, a exemplo dos chats. Nesse tipo de interatividade, a comunicação em tempo real possibilita aos envolvidos uma sensação de grupo, de comunidade, o que 
pode ter efeito positivo para preservar a motivação, a interação em tempo real, o retorno e a crítica imediata. Já as ferramentas de comunicação assíncronas são aquelas nas quais não se espera uma resposta imediata, as novas informações vão sendo registradas pouco a pouco. São exemplos de ferramentas de interação assíncrona o fórum, os blogs, arquivos disponibilizados, entre outros. As interações assíncronas tem como vantagem o fato de possibilitarem que o usuário faça sua intervenção de forma mais organizada, uma vez que ele terá tempo para sistematizar sua opinião, comentário respostas etc.

Quanto ao relacionamento mantido as interações podem ser classificadas como mútuas ou reativas. Uma interação reativa é sempre limitada para os atores, como a ação de clicar em um link. $O$ ator pode decidir apenas entre clicar ou não no link, e caso clique a resposta para essa interação já está previamente definida. A interação mútua, por outro lado, é sempre construída, negociada e criativa, como a que ocorre no espaço de comentários em um blog (PRIMO, 2003).

O que se procura então são maneiras de projetar recursos nas interfaces para conseguir que os usuários realizem o maior número possível de interações mútuas. Quanto maior for a quantidade de conversas enriquecidas por novas informações, troca de experiências, comentários, dúvidas e respostas, melhor poderá ser o resultado de aprendizagem oferecido por uma comunidade digital.

Sobre as características específicas de redes sociais projetadas para o aprendizado colaborativo, Dimitracopoulou (2005), baseado nas características das hipermídias e das redes sociais digitais, propôs algumas questões ou decisões de troca para delinear as diretrizes fundamentais de um projeto de aprendizado colaborativo. Para esta autora, atualmente, as principais opções (que deveriam ser) consideradas pelos designers estão relacionadas às principais funções da CSCL (Computer Suported Collaborative Learning):

- Os meios de diálogo (um aspecto sempre fundamental no aprendizado colaborativo) lida com ao menos três opções específicas: (i) entre o diálogo livre ou estruturado, (ii) entre ferramentas de comunicação paralelas ou embutidas, (iii) e entre ferramentas baseadas em texto ou oralidade;

- A opção entre ações coordenadas ou o diálogo (influência sobre a liberdade dos estudantes);

- A opção entre o suporte à meta-cognição para a auto-regulação ou suporte de professor;

- Uma opção mais genérica relacionada a projetar um sistema baseado em ações ou baseado em produção de texto (isso pode ter influência nas tendências de funcionalidades de um sistema) (DIMITRACOPOULOU, 2005, tradução nossa, p.3).

Nas plataformas virtuais, cada um é consumidor dos dados fornecidos pelos outros, ao mesmo tempo que produtor de seu "perfil" pessoal. No ciberespaço se leva a cabo uma hibridização dos papéis entre oferta e procura, entre produção, consumo e distribuição de dados (LIPOVETSKY; SERROY, 2011, p.372). De acordo com Primo (2000 apud FERREIRA; BIANCHETTI, 2002, p.260) "[...]As novas tecnologias da informação e da comunicação vêm contribuindo para a modificação da forma de as pessoas se relacionarem e de construírem conhecimentos, pois elas proporcionam múltiplas 
disposições à intervenção do interagente". É necessário então que os diversos setores da sociedade que desejem se comunicar de maneira mais eficiente se adaptem a essa maneira diferente de estabelecer diálogos e que se torne capaz lidar com uma quantidade cada vez maior e mais dispersa de informações para tornar os dado úteis e compreensíveis. Essas modificações impulsionadas pelos avanços da tecnologia tendem a ter impactos sociais em alguma medida irreversíveis na maneira como os indivíduos se comunicam, conforme explica Weissberg (2004).

Se considera que o efeito mais importante de uma tecnologia intelectual inédita é instituir, abrir uma nova maneira de cumprir certas atividades e de resolver problemas, então se compreende que sua extensão é uma conquista, uma colonização mental, com a diferença de que não poderia haver descolonização. Não há possibilidade de "desalfabetização", nem de "desdigitalização". (WEISSBERG, Op.Cit., p.113)

A inteligência coletiva proveniente das conexões em rede é definida por Pierre Levy (1999) como a inteligência distribuída por toda parte, incessantemente valorizada, coordenada em tempo real, que resulta em uma mobilização efetiva das competências. Essa inteligência coletiva é demonstrada justamente no aumento de produtividade de uma comunidade por meio do resultado desses processos de cooperação. Quando os indivíduos, ou atores, se libertam das limitações individuais e têm acesso, enquanto grupo, a uma maior variedade de experiências e conhecimentos provenientes das situações de conflito e competição, o grupo se torna capaz de evoluir e aprender coletivamente com mais eficiência (JENKINS, 2006).

Neste contexto, exige-se da escola, de quem quer que projete artefatos educacionais, e em particular do professor, a postura de não resistir às mudanças em curso nos processos comunicacionais mais usuais, mas de assumir a função de orientar os percursos individuais do saber e contribuir para o desenvolvimento de competências, habilidades e cidadania do aluno em meio a todas essas vias de comunicação e conteúdo. No entanto, nem sempre a rapidez das inovações tecnológicas é acompanhada em igual medida pela capacitação dos profissionais para lidar com essas inovações. Faz-se necessário que as escolas sejam munidas de ferramentas, conhecimentos e novas habilidades que permitam tirar proveito pleno das possibilidades apresentadas pelas tecnologias mais recentes. $O$ despreparo, muitas vezes, resulta no uso inadequado ou na falta de criação diante dos recursos tecnológicos disponíveis. É muito comum, por exemplo, que professores apenas incluam os recursos tecnológicos em suas aulas como um acessório dispensável, sem realizar necessariamente nenhuma alteração nos métodos pedagógicos que coloque o componente tecnológico no centro da atividade e tire proveito de todo o seu potencial hipermidiático. Ao fazer isso estão apenas adicionando uma camada desnecessária de carga cognitiva em suas aulas e assim, ao contrário do que possa parecer, dificultando ainda mais o aprendizado dos alunos. Torna-se fundamental que os profissionais compreendam profundamente as características das mídias que decidem utilizar para que consigam assim adaptar seus métodos de maneira mais consciente e consistente. 


\section{A INSTÂNCIA DO DESIGN NO PROPÓSITO DA INTERFACE}

As práticas de ensino à distância, embora venham há muitos anos se mostrando ferramentas importantes de difusão do conhecimento e de democratização da informação, colaborando, eficientemente, com a preparação de profissionais para o mercado de trabalho mundial são um dos exemplos de iniciativas de ensino não presencial apoiadas por algumas possibilidades tecnológicas recentes. No entanto, frequentemente as práticas atuais do ensino à distancia mediado por computadores limitam-se à disponibilizar conteúdo multimídia em uma estrutura curricular que se dispõe tão linear, pré-definida, padronizada e reativa, quanto uma enfadonha aula em sala tradicional com leitura seguida exercício de fixação, proveniente de ideias da revolução industrial. Nesse casos específico, embora aconteça à distância e mediada por tecnologias de comunicação, o projeto não necessariamente promove a colaboração entre os estudantes e a troca de experiências pessoais para a solução coletiva de problemas ou mesmo a personalização das lições, das estruturas e avaliações dos cursos.

Práticas pedagógicas que pretendam ser realmente inovadoras e eficazes no uso de tecnologias digitais de comunicação, condizentes com as exigências da sociedade contemporânea e, consequentemente, com as necessidades de aprendizagem dos alunos, envolverão o estabelecimento de novos significados para o ensinar e o aprender, promovendo uma relação em que as posições hierárquicas entre seus atores seja suprimidas ou reduzidas ao mínimo possível. Para Freire(1987), a colaboração entre os sujeitos deve estar no centro das atividades educacionais já que "ninguém educa ninguém, ninguém educa a si mesmo, os homens se educam entre si, mediatizados pelo mundo". A concepção de aluno necessita ser ampliada para contemplar, além das ações individuais, a interação deste com seus iguais para possibilitar que se caracterizem como protagonistas e construtores autônomos do próprio conhecimento num processo contínuo mediado pela linguagem.

A cooperação é o processo formador das estruturas sociais. Sem cooperação, no sentido de um agir organizado, não há sociedade. A cooperação pode ser gerada pelos interesses individuais, pelo capital social envolvido e pelas finalidades do grupo. Entretanto, é essencial para a compreensão das ações coletivas dos atores que compõem a rede social (RECUERO, 2010, p.81). O aprendizado colaborativo apoiado por computadores é definido por Dillenbourg, Jäverlä e Fischer (2009) como uma variedade de práticas educacionais nas quais a interação entre os pares constitui o fator mais importante para o aprendizado, sem excluir outros fatores como o material didático e a interação com professores. Torres (2005) ainda acrescenta à sua definição outros itens mais específicos como a flexibilização dos papéis no processo de comunicação e das relações a fim de permitir a construção coletiva do saber, a aceitação das diversidades e diferenças entre os alunos, o desenvolvimento da autonomia do aluno no processo ensino-aprendizagem, a valorização da liberdade com responsabilidade, o comprometimento com a autoria e a valorização dos processos e não apenas do produto. A colaboração por si só não produz efeito cognitivo, seus resultados dependem da extensão do engajamento do grupo em interações produtivas. Embora não tenha como se comprovar que sirva como substituto direto para o ensino ou treinamento formal e sim como alternativa complementar, o aprendizado colaborativo, tem como proposta que os estudantes trabalhem juntos 
para maximizar o seu aprendizado individual tanto quanto o dos demais atores da rede. Nas condições ideais, o aprendizado colaborativo deve permitir que todos os atores da rede tenham um resultado que exceda a soma das partes, ou seja, que os atores da rede, enquanto grupo, atinjam resultados melhores do que atingiriam trabalhando isolados (JOHNSON e JOHNSON, 1999).

A tendência de convergir aprendizagem mediada por artefatos digitais e aprendizagem convencional, com simultaneidade entre atividades presenciais e virtuais em proporções variadas tem sido chamada de "ensino híbrido" ou "blended learning". O ensino híbrido é caracterizado por uma série de estratégias de gestão atividades educacionais adaptáveis, que tiram proveito tanto do espaço físico quanto do ciberespaço para amplificar as possibilidades de aprendizagem do aluno.

Ainda que não tenham plena consciência, muitos professores e alunos já encontram e utilizam métodos empíricos para enriquecer suas propostas de ensino e aprendizado ao se apropriar dos laços das redes sociais para se comunicar e propor aos alunos que colaborem uns com os outros, acessem e disseminem informações e se utilizem dos conteúdos disponíveis nos ambientes digitais e até mesmo da biblioteca e dos laboratórios das escolas. Muitos dos recursos já existentes e comuns entre diversas plataformas como grupos de mensagens, fóruns, blogs, canais de vídeo, wikis e outras que poderão surgir, vem sendo utilizados como ferramentas reutilizáveis ou referências para a criação de novas tecnologias e interfaces adaptadas para o desenvolvimento de comunidades digitais de aprendizagem colaborativa mais eficazes.

Entretanto, para que essas novas proposições e soluções sejam eficientes será necessário que se estabeleçam diretrizes que considerem as características do hipertexto e da hipermídia, entendam como se dão os processos comunicacionais em redes sociais e mais especificamente, compreendam as estratégias, ferramentas e métodos específicos do design de informação, interação e de interfaces que possam motivar a colaboração entre seus usuários. Da mesma maneira, será necessário compreender as teorias relativas ao aprendizado colaborativo para relacioná-las a estudos da cibercultura e do design de interações e interfaces.

Para Alarcón \& Mardones (1998), geralmente (e infelizmente), é durante a fase de execução e implantação dos projetos em que são detectados os principais defeitos de design:

1. Design de baixa qualidade: O design do sistema pode ser incompleto, ou mesmo conter elementos não explicitados devidamente, induzindo à baixa inteligibilidade, exigindo uma grande quantidade de instruções complexas adicionais. As instruções, enquanto informações mais detalhadas, segundo os autores, são mais difíceis de serem processadas, e na maioria das vezes, são ignoradas. Muitas das vezes, as interfaces de design têm inconsistências, erros e omissões, ou simplesmente apresentam falta de clareza em sua apresentação. Isto implica que aqueles que devem se beneficiar da plataforma não tem acesso a todas as informações necessárias ou mesmo podem vir a ter a informação errada para desenvolver a atividade de aprendizado ou de comunicação.

2. Falta de Padrões de Projeto: Para os autores, há uma falta de padrões nos projetos e falta de aptidão para lidar com a tecnologia existente. Em muitos 
projetos de características semelhantes, ou do mesmo tipo, os designs utilizados são completamente diferentes, com a consequente perda de eficiência na fase de assimilação e familiarização.

3. Falta de Construtibilidade: Uma proporção importante dos problemas detectados por estes autores, durante a concepção dos sistemas é devido à falta de construtibilidade nos projetos de design - por desconhecimento, ou mesmo falta de capacitação dos executantes - o que determinou a ineficácia de grande parte das plataformas avaliadas, com perdas de diferentes tipos e magnitudes.

Segundo Mayer (2011), quando a mensagem é pobremente desenhada, os alunos têm mais dificuldade em compreendê-la, sendo a carga cognitiva extrínseca elevada. Quando a mensagem está bem estruturada e apresentada, a carga cognitiva é minimizada.

Os designers poderiam intervir exatamente nesse ponto, pois eles dominam ou deveriam dominar - os meios para reduzir a complexidade cognitiva e contribuir para apresentar informação de forma útil, desenvolvendo uma interface adequada entre a informação e o usuário/leitor. Esse novo tipo de design é conhecido por diferentes denominações, como arquitetura da informação ou engenharia do conhecimento. Prefiro o termo 'design de informação' usado na Europa, cujo objetivo consiste em fomentar o metabolismo cognitivo, vale dizer, facilitar a assimilação de informação.(BONSIEPE, 2011, p.83)

As metodologias e a lógica dedutiva do design podem contribuir na elaboração e prototipagem de serviços e interações digitais eficientes para estimular a colaboração e registrar e avaliar o aprendizado individual resultante de processos colaborativos. De Moraes (2010) afirma que a sociedade passou da técnica para a Cultura Tecnológica e do projeto para a Cultura Projetual. Essas transformações aumentaram o raio de ação dos designers e a complexidade de sua atuação. Portanto, os designers devem preparar-se para, ao invés de aguardar a consolidação da complexidade em paradigma, lidar com as mudanças e participar delas enquanto interpretam, antecipam ou prospectam novos cenários. Para Bonsiepe (2015), o designer gráfico se transforma em information manager. Isso requer um trabalho cognitivo e organizado que, no ensino de design atual, é tratado com alguma indiferença. Além disso, design se refere a um tipo especial de ação inovadora, que cuida das preocupações de uma comunidade de usuários. Design sem componente inovador é, obviamente, uma contradição.

\section{CONCLUSÃO}

Para projetar atividades educacionais eficientes em redes sociais digitais, tornase importante que designers e educadores compreendam como ocorre a colaboração mediada por essas redes, o que a motiva e quais as recompensas envolvidas para aquele que investe seu tempo colaborando. Os designers tem potencial para tomarem para si o papel de encontrar maneiras de reduzir a carga cognitiva de todo o fluxo informacional estabelecendo significados através da organização dos dados. Além disso são capazes de pensar em maneiras de estimular, a partir do design de interfaces, as interações que estejam de acordo com objetivos e prioridades 
específicas dos usuários de cada ambiente virtual. Torna-se necessário para isso que sistematizem e compreendam quais são precisamente os elementos de design de informação e interface que podem ser estratégicos para motivar a colaboração entre os usuários da rede. Descobrir, por exemplo, quais dados de desempenho ou participação precisam ser exibidos em destaque para os usuários, quais os perfis de uso possíveis dentro de um público específico, e de que maneiras é possível tornar o processo de participar das atividades mais recompensador emocionalmente, em especial para aqueles usuários com maior tendência a não-participação, para que os resultados médios de colaboração validem os esforços de todos os interagentes.

Como parte de equipes multidisciplinares os designers devem ter a competência de não somente a solucionar problemas já postos, mas também a capacidade de interpretar o mundo em suas mediações e partir em busca da proposição ativa de problemas que pode ser capaz de identificar e solucionar de maneira elegante, inovadora e desejável pelo público. No campo da aprendizagem colaborativa em redes sociais digitais há inúmeras questões ainda em aberto que podem ser pensadas sob a perspectiva do design. Os processos e metodologias de projeto podem e devem ser aplicados desde a concepção do serviço propriamente dito, das próprias diretrizes de conversação da comunidade e sistema de recompensas até aplicações mais diretas de design de informação e interface na adequação da arquitetura das infromações e da estética gráfica de cada uma das páginas. Todos seriam fatores de grande influência na percepção dos usuários e por consequência nos resultados de colaboração e aprendizagem de todo o grupo.

\section{REFERÊNCIAS}

ALARCÓN, Luis F.; MARDONES, Daniel A. Improving the design-construction interface. In: Proceedings of the 6th Annual Meeting of the International Group for Lean Construction. 1998.

BONSIEPE, Gui. Design, Cultura e Sociedade. São Paulo: Blucher, 2011.

BONSIEPE, Gui. Do material ao digital. São Paulo: Blucher, 2015.

DE MORAES, Dijon. Metaprojeto como modelo projetual. Strategic Design Research Journal, v. 3, p. 62-68, 2010.

DILLENBOURG, Pierre; JÄRVELÄ, Sanna; FISCHER, Frank. The Evolution of Research on Computer Supported Collaborative Learning: From Design to Orchestration. In: BALACHEFF, Nicholas; LUDVIGSEN, Sten; JONG, Ton; LAZONDER, Ard; BARNES, Sally; (organizadores) Technology-Enhanced Learning: Principles and Products. Springer, 2009.

DILLENBOURG, Pierre. What do you mean by collaborative learning? Coginitive and computational approaches. Oxford: Elsevier, pp 1-19, 1999.

DIMITRACOPOULOU, Angelique. Designing Collaborative Learning Systems: Current Trends \& Future Research Agenda. University of Aegan, Greece. 2005.

FERREIRA, Simone; BIANCHETTI, Lucídio. As tecnologias da informação e da comunicação e as possibilidades de interatividade para a educação. Revista da FAEEBA

- Educação e Contemporaneidade, Salvador, v13, n.22, 2004. 
HCM Advisory Group; SABA; A pulse on social learning. 2013.

Instituto Brasileiro de Geografia e Estatística - IBGE. Pesquisa nacional por amostra de domicílios: Acesso à internet e à televisão e posse de telefone móvel celular para uso pessoal 2013. IBGE, 2015.

JENKINS, Henry. Fans, Bloggers and Gamers. NYU Press, 2006.

JOHNSTON, David W; JOHNSTON, Roger T. Making cooperative learning work. Ohio State University, College of Education. 1999.

LEVY, Pierre; A inteligência coletiva. São Paulo: Edições Loyola, 1999. 217p.

POLAINE, Andy; LOVLIE, Lavrans; REASON, Ben. Service design: from insight to implementation. New York: Rosenfeld Media, 2013. 202p.

PREECE, Jennifer; ROGERS, Yvonne; SHARP, Helen. Design de Interação: Além da interação humano-computador. São Paulo: Bookman Editora, 2013.

PRIMO, Alex. Interação Mediada por computador: comunicação, cibercultura, cognição. Porto Alegre: 2a Edição, Sulina, 2008. (Coleção: Cibercultura) 240p.

RECUERO, Raquel. Redes sociais na internet. Porto Alegre: Sulina, 2010. (Coleção Cibercultura) 191p.

SOUZA Renato Rocha. Aprendizagem Colaborativa em Comunidades Virtuais. Florianópolis, 2000 106f. Dissertação (Mestrado em Engenharia de Produção) Programa de Pós-graduação em Engenharia de Produção, UFSC, 2000.

SOUZA, Renato R. Aprendizagem Colaborativa em Ambientes Virtuais. Universidade Federal de Santa Catarina, 2000.

STICKDORN, Marc; SCHNEIDER, Jakob. This is service design thinking. Hoboken, New Jersey: John Wiley \& Sons, 2011. 373p.

TORRES, Patrícia Lupion. Laboratório online de aprendizagem: uma proposta crítica de aprendizagem colaborativa para a educação. Tubarão: Ed. Unisul, 2004.

TORRES, Tércia Zavaglia, AMARAL, Sérgio Ferreira do. Aprendizagem Colaborativa e Web 2.0: proposta de modelo de organização de conteúdos interativos. Campinas, 2011.

WEISSBERG, Jean-Louis. Paradoxos da Teleinformática. In: PARENTE, André (organizador) Tramas da Rede: novas dimensões filosóficas, estéticas e políticas da comunicação. Porto Alegre: Sulina, 2004. 303p. 